\title{
Harmonic Scalpel versus Conventional Technique of Tonsillectomy- A Prospective Study
}

\author{
Kumaran Alias Ramesh Colbert ${ }^{1}$, A. Dayanand ${ }^{2}$, M. Ravi Sankar ${ }^{3}$ \\ ${ }^{I}$ (Associate Professor, Department of Otorhinolaryngology, Indira Gandhi Medical College \& Research \\ Institute, Puducherry, Pondicherry University, India) \\ ${ }^{2}$ (Associate Professor, PSG Institute of Medical Sciences \&Research, Coimbatore, M.G.R.University \\ Tamilnadu, India) \\ ${ }^{3}$ (Senior Resident, Department of Otorhinolaryngology, Indira Gandhi Medical College \& Research Institute, \\ Puducherry, Pondicherry University India)
}

\begin{abstract}
Tonsillectomy is the one of the most commonly performed surgical procedure in the department of otorhinolaryngology. There are different methods of tonsillectomy techniques used today with the aim of providing more comfort and less morbidity to patients. Postoperative bleeding and Pain are the most common complications. This study evaluated the Operative time, Intraoperative blood loss, Postoperative pain ,Hospital stay and Cost effectiveness of tonsillectomy performed by Harmonic scalpel as compared to Conventional dissection technique. This is a prospective randomized study where in fifty patients were divided into two groups of equal number. In one group, the tonsillectomy was performed by Harmonic scalpel and in the other group by Conventional dissection technique. Amount of blood loss is significantly reduced in the harmonic group. Total postoperative pain and operative time slightly higher for harmonic scalpel group. There is no significant difference in hospital stay and post operative complications. Harmonic scalpel tonsillectomy has shown to be useful, safe, easy and reliable method of performing tonsillectomy.
\end{abstract}

Key words: Harmonic scalpel, Tonsillectomy.

\section{Introduction}

Faucial tonsil also called as palatine tonsil is an aggregate of lymphoid tissue located in the lateral wall of oropharynx between palatoglossal and palatopharyngeal muscle folds. Tonsil is important in children for defense against micro organisms particularly by producing IgA local antibodies. Some times their protective mechanism fails and become source of infection or it cause anatomical air way obstruction in oropharynx and leads to local or systemic complications this requires removal of tonsil. Surgery of tonsil was first attempted by Celsius in $300 \mathrm{BC}$. There after only partial removal of tonsil was practiced for several centuries . An American surgeon reported the use of first tonsiliectomy by Guillotine in $1867 .{ }^{1}$ In the modern day practice Dissection and snare and Electrocautery are the most commonly used methods. However, the Dissection technique has remained the standard surgical technique for tonsillectomy for many years till now. The various methods were introduced with aim of reducing complications and to improve the quality of life. Available technique include cold -knife dissection, Electrocautery, Cryogenic tonsillectomy ,Coblation technique Laser tonsillectomy and Harmonic scalpel tonsillectomy ${ }^{2,3}$. Recent years researches ${ }^{2}, 6-9$ found harmonic scalpel is an important emerging tool in tonsillectomy which is safe, simple, reliable, and easy to perform.

The harmonic scalpel is an ultrasonically activated surgical device which can cut and coagulate the vessels or tissues at low temperature. It does not conduct electric current and has high activity of hemostasis. It controls bleeding by coaptive coagulation at low temperature ranging from 50 to $100^{\circ} \mathrm{c}$. the vessels are coapted (tamponade) and sealed by protein coagulation. The sharp blade of harmonic scalpel vibrates at a frequency of $55.5 \mathrm{kHz}$ over a distance of 80 micro m. The coagulation mechanism of harmonic scalpel occurs through the transfer of mechanical energy to tissues by breaking tertiary hydrogen bonds to denature protein and by generation of heat from internal tissue fraction by means of high frequency vibration of tissue.

Therefore the present prospective study was designed to evaluate intraoperative records and post operative outcomes of standard dissection snare technique and harmonic scalpel technique.

\section{Discussion}

Otolaryngologists around the globe opt for various modalities of instrumentation to reduce the morbidity tonsillectomy to the patient. Harmonic scalpel tonsillectomy has become more popular in the first decade of this century.the studies published by Stuart A.Morgenstiein etal ${ }^{7}$, advantages of harmonic scalpel tonsillectomy constributing to its popularity amongst otoaryngologists with evidence of redction in morbidity.The studies by Renee $\mathrm{at}^{\mathrm{al}^{8}}$ and N.N Dutta et $\mathrm{al}^{9}$ showed there was significant decrease in the intraoperative blood loss in harmonic scalel method. In the study by Renee walker et $\mathrm{al}^{8}$ the average blood loss 
was less than $30 \mathrm{ml}$.in our study, the average blood loss was $12.5 \mathrm{ml}$ when compared to $60.2 \mathrm{ml}$ by dissection and snare method is statistically very significant(p value -0.001$)$. The evidence of postoperative haemorrhage (primary and secondary) were found to be unaffected by surgical methods was noted in Cochrane review by pinder Detal ${ }^{10}$. In the our study, one patient had secondary hemorrhage who had undergone standard dissection tonsillectomy and none of the patients in harmonic scalpel group.

Postoperative pain is less in harmonic scalpel to nsillectomy in the studies conducted by Dutta et al ${ }^{9}$ our .In our study we quantified and compared post-tonsillectomy pain using wong Baker pain scale, it was observed that there is a slight increase in postoperative pain for this harmonic scalpel group during the initial two post operative days this is in contrast to the study by Stuart A.Morgenstiein et $\mathrm{al}^{7}$ who found no significant difference between the two methods. But at second and fourth week postoperatively, the pain is less or equal to that of standard dissection group.

Harmonic scalpel tonsillectomy being a bloodless surgery and this technique most ideal for patients with bleeding disorders like factor VII deficiency, anemia,patients on anticoagulant therapy and in small children according to Brian J. Wiatrak te $\mathrm{al}^{2}$. The Advantages of harmonic scalpel tonsillectomy are the precision of application, minimal damage to adjacent normal tissues, minimal postoperative side effects and complications.

The use of Visual analogue scale for pain assessment has been criticized by some as being subjective as opposed to other parameters like analgesic intake and return to normal activity, but ultimately all pain assessment scales are subjective relaying on the patients perceptions. The main disadvantage of this study was the additional cost factor. In our study, there was a 15\% increase in cost of surgery in patients who underwent harmonic scalpel tonsillectomy.

\section{Materials And Methods}

This prospective study was carried out from November 2002 to may 2004 at P.S.G institute of medical Sciences and research ,Coimbatore ,Tamilnadu, India .Patients included in the study were in the age group of 3 to $30 \mathrm{yrs}$ with clear indications for tonsillectomy( recurrent tonsillitis and obstructive tonsillar hypertrophy) with or without adjunctive procedures like Adenoidectomy and Grommet insertion.

Patients were randomly divided into groups, one group underwent Tonsillectomy by harmonic scalpel where as the second group underwent tonsillectomy by Dissection and snare method. All patients were admitted a day prior to surgery and were started on prophylactic antibiotics. The sizes of tonsil were graded according to Brodskys ${ }^{4}$ classification. Routine blood investigations and x-ray nasopharynx (lateral view) were done for adenoid hypertrophy.

The operation was done under general anesthesia using endotracheal intubation ,the patient in Rose position, the mouth held open by Boyle dav is mouth gag supported by draffins bipods. One group of patients under went harmonic scalpel unit, the setting used being 3.(fig 1).Incision is made on the anterior pillar from superior pole to inferior pole using hook scalpel(fig 2) blade of the harmonic scalpel was used for tonsil dissection. The other group of patients underwent tonsillectomy by dissection and snare method by a palatoglossal incision followed by dissection in the peri tonsillar plane, completed using a tonsillar snare(fig 3).

The operating time was measured from insertion of boyle davis mouth gag to removal of both tonsil. The suction tube was attached with mucus extractor (fig 3) during surgery to record an accurate intraoperative blood loss. Post operative pain was assessed by princess Margaret hospital pain assessment tool using wong baker faces pain rating scale ${ }^{5}$ on the night of surgery, after $24 \mathrm{hrs}, 1^{\text {st }}, 2^{\text {nd }}$ and $4^{\text {th }}$ weeks following surgery. Pain score was obtained by the visual analogue score made by the patient attenders and nursing staff who were educated about this scoring ranging from 0 to 2. Any post operative complication was recorded . Total cost of surgery was obtained from the billing section of the hospital. All patients were reviewed in the out patient department at the end of $1^{\text {st }}, 2^{\text {nd }}$ and $4^{\text {th }}$ weeks. Clinical data of each patient was recorded in the Performa made for this purpose.

\section{Results}

Fifty patients were included in this study out of which 25 patients( group I) were under standard dissection and snare tonsillectomy and other 25 patients(group II) were under harmonic scalpel tonsillectomy.

Age distribution:

Group I mean age was 12.5 (range 3-22 yrs)

Group II mean age was 17 (range 4 -30 yrs)

Gender distribution:

12 male and 13 female patients in standard dissection and snare group. In harmonic scalpel group there were 13 male and 12 female patients. 
The main indication for tonsillectomy in our patients included recurrent tonsillitis, persistent sore throat, persistent dysphagia due to tonsillar hypertrophy.

\section{Operating Time}

The mean operating time for standard dissection and snare technique was 25.2minutes( range 25-35 minutes) for harmonic scalpel group the mean time was 36 minutes( range 30- 45 minutes). The statistical analysis of data shows that mean time was higher for harmonic scalpel group but it was not significant ( $\mathrm{p}$ 0.130). The average intraoperative blood loss for standard dissection and snare technique was 60.2ml( range 30$90 \mathrm{ml}$ ) for hormonic scalpel group average was $12 \mathrm{ml}($ range $10-20 \mathrm{ml}$ ).this was statistically significant (p0.001).(Table 1)

Table 1:

\begin{tabular}{|c|c|c|c|c|c|c|c|}
\hline & \multicolumn{3}{|c|}{ DISSECTION AND SNARE } & \multicolumn{3}{c|}{ HORMONIC SCALPEL } & \multirow{2}{*}{ P-VALUE } \\
\cline { 2 - 7 } & MINIMUM & MEAN & MAXIMUM & MINIMUM & MEAN & MAXIMUM & \\
\hline $\begin{array}{c}\text { OPERATIVE } \\
\text { TIME } \\
\text { (MINUTES) }\end{array}$ & 20 & 25.2 & 35 & 30 & 36 & 45 & 0.130 \\
\hline $\begin{array}{c}\text { OPERATIVE } \\
\text { BLOOD } \\
\text { LOSS(ml) }\end{array}$ & 30 & 60.2 & 90 & 10 & 12 & 20 & 0.001 \\
\hline
\end{tabular}

\section{V1. Postoperative Pain}

Postoperative time was observed by princes Margaret hospital pain assessment tool (PMHPT) using Wong-Baker faces pain rating scale. The majority of the standard dissection method patients had minimal pain for first 48 hours, especially on the night of surgery and 24 hours after which the pain gradually decreased. There was no significant difference in pain at the end of first week and second weeks between harmonic scalpel and dissection and snare cases.

\section{Postoperative Complications}

In this comparative study,we observed only one patient who had undergone tonsillectomy by dissection and snare method had secondary hamorrage, managed successfully with intravenous antibiotics. No one in harmonic scalpel group had any type of bleeding.

\section{Hospital Stay}

The average hospital stay for both the groups were two days,Almost all the patients in each group were discharged on the Second postoperative day

\section{Wound Healing}

Wound healing in the tonsillar fossa was assesed subjectively by noting the amount of slough , the degree of mucosal re-epithelialisation and the surounding erythema. Two patients in the harmonic scalpel group had congestion and edema of uvula with eschar formation in the tonsillar fossa.

\section{The Cost of Surgery}

Cost of surgery was slightly more (12\% to $15 \%$ ) for harmonic scalpel group as compared to standard dissection group. Patients in both the groups were able to resume their normal activity on an average on the seventh postoperative day.

\section{Conclusion}

In this study the harmonic scalpel tonsillectomy using harmonic scalpel unit has been shown to be useful safe easy and reliable method of performing tonsillectomy. The single most important advantage of harmonic scalpel tonsillectomy is the excellent hemostasis intraoperatively and there by minimizing the blood loss during procedure. This hemostatic property is an advantage in patients with fibrotic tonsil and will prove useful in patients with bleeding disorders. Harmonic scalpel had increase postoperative pain though this was statistically not significant. No primary reactionary or secondary bleeding occurred in our study hence can be a useful tool as daycare surgery. Duration of surgery slightly more, by virtue of technique coaptation and this is not surgeon dependent .Cost factor is more than conventional method by $15 \%$ which is likely to reduce if more cases are done in future using this technique. As this is a newer technology, further larger studies are required to confirm the advantages and disadvantages. 


\section{References}

[1]. Curtin JM. The history of tonsil and adenoid surgery. Otolaryngol Clin North Am. 1987 May;20(2):415-9.

[2]. Wiatrak BJ, Willging JP. Harmonic scalpel for tonsillectomy. Laryngoscope. 2002;112(8 Pt 2 Suppl 100):14-6.

[3]. Derkay CS, Maddern BR. Innovative techniques for adenotonsillar surgery in children: introduction and commentary. Laryngoscope. 2002;112(8 Pt 2 Suppl 100):2

[4]. Brodsky L, Moore L, Stanievich JF: A comparison of tonsillar size and oropharyngeal dimensions in children with obstructive adenotonsillar hypertrophy. Int J Pediatr Otorhinolaryngol 1987; 13:149

[5]. Wong D backer : pain in children and comparison of assessment scales. Pediatric nursing 1988;14:9-17.

[6]. Sood S,Corbridge R,Powles $\mathrm{J}$ et al; Effectiveness of the ultrasonic harmonic scalpel for tonsillectomy. Ear Nose and Throat jornal.2001;80:514-18.

[7]. Morgenstein SA,Jacobs HK, Brusca PA,Consiglio AR, DonzelliJ, Jakubiec JA, DonatTL. A comparison of tonsillectomy with the harmonic scalpel versus electrocautery. Otolaryngol Head Neck Surg.2002 Oct 127(4):333-8.

[8]. Walker RA, Syed ZA. harmonic scalpel tonsillectomy versus electrocautery tonsillectomy; a comparative pilot study. Otolaryngol Head Neck surg. 2001 Nov 125 (5):449-55

[9]. Dutta NN, Bordoloi BM: tonsillectomy using harmonic scalpel. Indian J Otolaryngol Head Neck surg 2002;jan 54(1):74-6.

[10]. Pinder D,Hilton M: dissection versus diathermy for tonsillectomy.Cochrane Database Syst Rev.2001;(4)

\section{FIGURE1: HARMONIC SCALPEL UNIT}

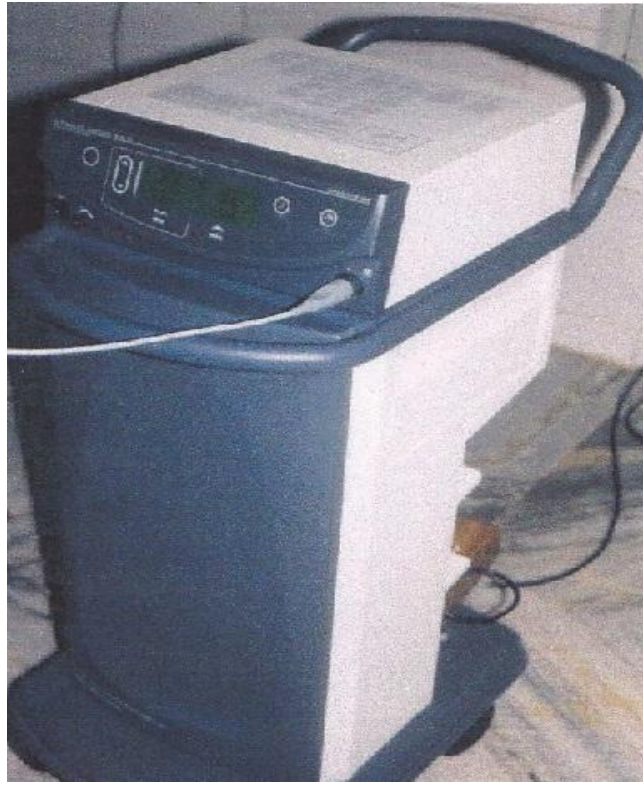

FIGURE 2: HARMONIC SCALPEL BLADE

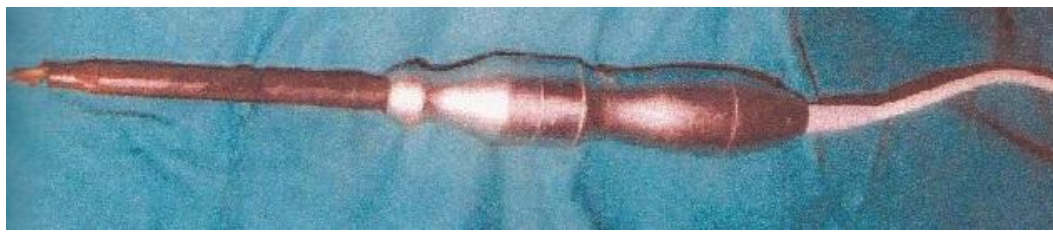

FIGURE 3: MUCOUS EXTRACTOR

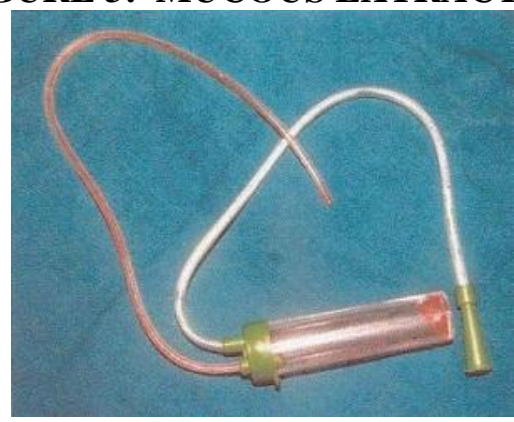

